\title{
Photochromic diarylethene ligands featuring 2-(imidazol-2- yl)pyridine coordination site and their iron(II) complexes
}

\author{
Andrey G. Lvov ${ }^{* 1}$, Max Mörtel ${ }^{2}$, Anton V. Yadykov ${ }^{1}$, Frank W. Heinemann², \\ Valerii Z. Shirinian ${ }^{1}$ and Marat M. Khusniyarov ${ }^{* 2}$
}

\section{Letter}

Address:

${ }^{1} \mathrm{~N}$. D. Zelinsky Institute of Organic Chemistry, Russian Academy of Sciences, 47, Leninsky prosp., 119991 Moscow, Russian Federation and ${ }^{2}$ Department of Chemistry and Pharmacy, Friedrich-Alexander University Erlangen-Nürnberg (FAU), Egerlandstraße 1, 91058 Erlangen, Germany

\section{Email:}

Andrey G. Lvov* - Ivov-andre@yandex.ru; Marat M. Khusniyarov* marat.khusniyarov@fau.de

* Corresponding author

\section{Keywords:}

diarylethene; 2-(imidazol-2-yl)pyridine; iron(II) complex;

photochromism

\author{
Beilstein J. Org. Chem. 2019, 15, 2428-2437. \\ doi:10.3762/bjoc. 15.235 \\ Received: 25 June 2019 \\ Accepted: 27 September 2019 \\ Published: 15 October 2019 \\ This article is part of the thematic issue "Molecular switches". \\ Guest Editor: W. Szymanski \\ (C) 2019 Lvov et al.; licensee Beilstein-Institut. \\ License and terms: see end of document.
}

\begin{abstract}
A new family of photochromic diarylethene-based ligands bearing a 2-(imidazol-2-yl)pyridine coordination unit has been developed. Four members of the new family have been synthesized. The photoactive ligands feature non-aromatic ethene bridges (cyclopentene, cyclopentenone, and cyclohexenone), as well as closely spaced photoactive and metal coordination sites aiming a strong impact of photocyclization on the electronic structure of the coordinated metal ion. The ligands with cyclopentenone and cyclohexenone bridges show good cycloreversion quantum yields of $0.20-0.32$. The thermal stability of closed-ring isomers reveals half-lives of up to 20 days in solution at room temperature. The ligands were used to explore coordination chemistry with iron(II) targeting photoswitchable spin-crossover complexes. Unexpectedly, dinuclear and tetranuclear iron(II) complexes were obtained, which were thoroughly characterized by X-ray crystallography, magnetic measurements, and Mössbauer spectroscopy. The formation of multinuclear complexes is facilitated by two coordination sites of the diarylethene, acting as a bridging ligand. The bridging nature of the diarylethene in the complexes prevents photocyclization.
\end{abstract}

\section{Introduction}

Transition metal complexes with photoactive ligands are of great interest for advanced photonic applications [1-7]. Reversible change of the electronic structure of diarylethene photo-

chromes [8-10] upon photocyclization is a promising tool to control the electronic structure of coordinated metal ions and, consequently, associated properties. Thus, diarylethenes were 
integrated into well-known ligand systems, including 1,10phenanthroline, 2-(azol-2-yl)pyridine, and related frameworks to yield photochromic ligands. The latter can be divided into two groups based on the position of the metal coordination site relative to the photoactive hexatriene unit of a diarylethene. Some diarylethene-based ligands with pendant coordination sites were synthesized, which allowed the remote control of luminescent, nonlinear optical and magnetic properties of transition metal complexes to some extent [11-16]. However, a close arrangement of hexatriene and coordination sites is the preferred approach for achieving a strong impact of the photochromic reaction on the electronic structure of a coordinated metal ion.

Previously reported examples of the second group ligands are collected in Figure 1. Yam et al. developed diarylethenes I [17] and II [18] and synthesized their rhenium(I) complexes, which possess prominent luminescent and spectral properties, including photocyclization with visible and NIR light. Using the photochromic ligand I, a spin-crossover (SCO) Fe(II) complex was developed, which allowed a reversible paramagnetic (high-spin, $S=2$ ) $\rightarrow$ diamagnetic (low-spin, $S=0$ ) transition at the iron(II) ion at room temperature (rt) in solution via ligand photocyclization [19]. More recently, the remarkable photoswitching between high-spin and low-spin states at $\mathrm{rt}$ in the solid state and thin films was demonstrated [20-22]. Kawai et al. obtained a luminescent complex of europium(III) with terarylene III showing the photomodulation of emission intensity [23]. A number of diarylethene ligands with a perfluorocyclopentene bridge were designed. $\mathrm{Yu}$ and co-workers reported a series of 2-(thiazol-2-yl)pyridine derivatives [24-26]. Reversible photoinduced release and trapping of copper(II) ions was achieved with IV. Diarylethene $\mathbf{V}$ and its analogs were used as chemical sensors for a number of metal ions [27].

Despite of recent advances in this area, the scarcity of reported examples requires the search and design of novel photoswitchable ligands with advanced properties. In this context, it is important to specify some design principles for such ligands. Firstly, novel ligands should feature a non-aromatic ethene bridge to increase the life-time of a photoinduced closed-ring isomer [28]. Secondly, photoactive hexatriene and metal coordination sites should be close to each other.

To meet these requirements, a new family of ligands VI based on the 2-(imidazol-2-yl)pyridine unit as a heteroaryl moiety and various ethene bridges is presented in this work. Diarylethenes with the 2-(imidazol-2-yl)pyridine being a part of the ethene bridge were previously developed [18,29] and their complexes with rhodium(I) [18], platinum(II) [30], and iridium(III) [31] were reported. In contrast, in our work, the 2-(imidazol-2yl)pyridine unit is used as a heterocyclic moiety of diarylethenes with cyclopentenone, cyclopentene, and cyclohexenone ethene bridges. The novel ligands have been tested in the coordination chemistry with iron(II) aiming photoswitchable SCO systems.
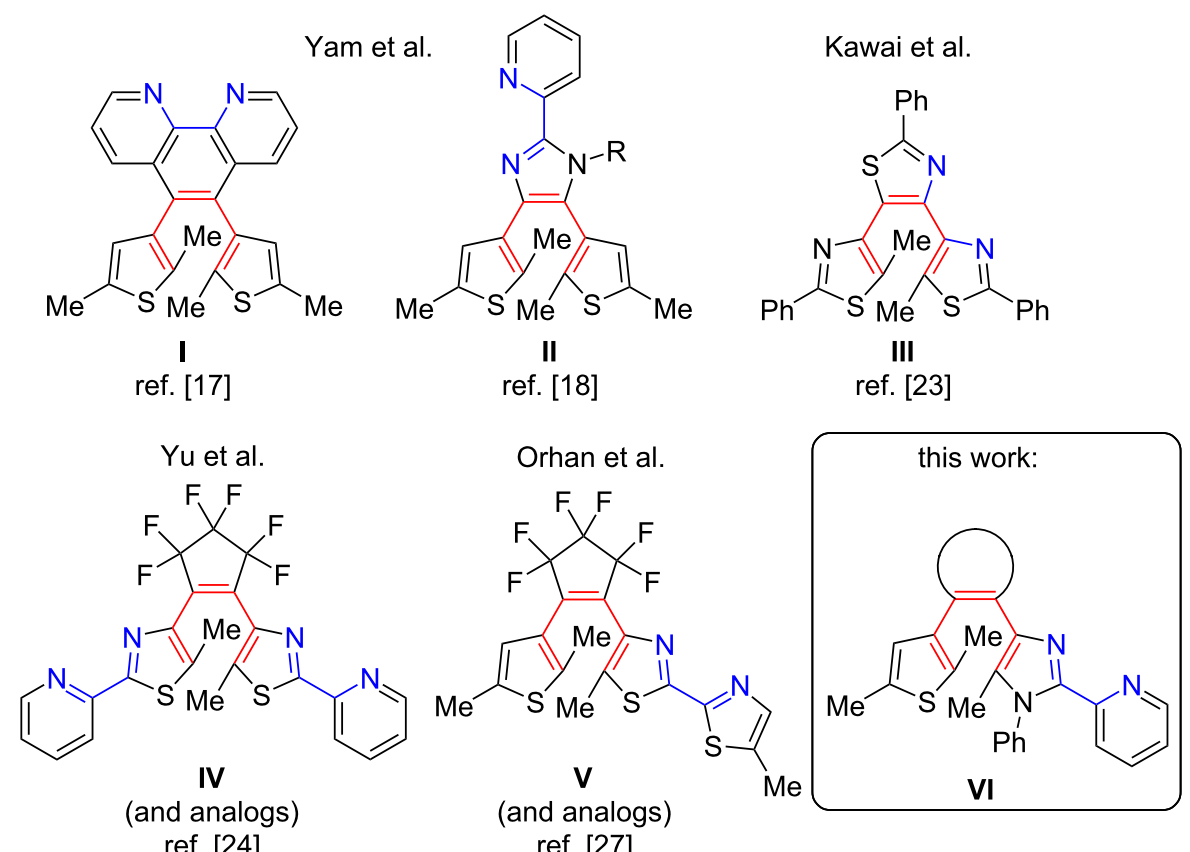

ref. [24] ref. [27] 


\section{Results and Discussion}

\section{Synthesis and structure of photochromic ligands}

Recently, some of us have developed original methods for the synthesis of various diarylethenes with cyclopentenone, cyclopentene, and cyclohexenone bridges [32]. These methods utilize ethyl 4-(2,5-dimethylthiophen-3-yl)-3-oxobutanoate (Scheme 1) or its analogs as starting materials. To obtain novel diarylethenes with 2-(imidazol-2-yl)pyridine moiety, here we have synthesized a previously unknown imidazole derivative 1 by a one-pot condensation [33] of 3-(hydroxyimino)pentane2,4-dione, aniline, and 2-pyridinecarboxaldehyde (Scheme 1).
The structure of $\mathbf{1}$ was confirmed by X-ray crystallography [34]. The ketone 1 was subsequently used for the synthesis of desired photochromic ligands with cyclopentenone (3), cyclopentene (4), and cyclohexenone (6 and 7) bridges via intermediate bromoketone 2 and chalkone 5. Cyclopentenone 3 was synthesized by adapting a previously reported two-step protocol [35] starting from ethyl 4-(2,5-dimethylthiophen-3-yl)3-oxobutanoate and bromoketone 2. Ionic hydrogenation [36] of $\mathbf{3}$ provided diarylethene $\mathbf{4}$ with a cyclopentene bridge with $51 \%$ yield. Robinson-type reaction [37] of ethyl 4-(2,5dimethylthiophen-3-yl)-3-oxobutanoate and chalkone 5 resulted in cyclohexenone derivative 6 (57\% yield). The saponification/

synthesis of key building-block<smiles>CC(=O)C(=NO)C(C)=O</smiles>
$\mathrm{H}_{2} \mathrm{~N}-\mathrm{Ph}$<smiles>CC(=O)c1nc(-c2ccccn2)n(-c2ccccc2)c1C</smiles>

1

synthesis of diarylethenes with 5-membered bridges<smiles>CC#CCCCCCCCC(=O)c1nc(-c2ccccn2)n(-c2ccccc2)c1C</smiles>

2<smiles>Cc1csc(C2=C(c3nc(-c4ccccn4)n(C)c3-c3ccccc3)CCC2=O)c1</smiles>

3<smiles>CC(C)C1CC(C2COOOO2)C(C2CCOCC2)C1C</smiles>

synthesis of diarylethenes with 6-membered bridges<smiles>Cc1c(C(=O)/C=C/c2ccccc2)nc(-c2ccccn2)n1-c1ccccc1</smiles>

5

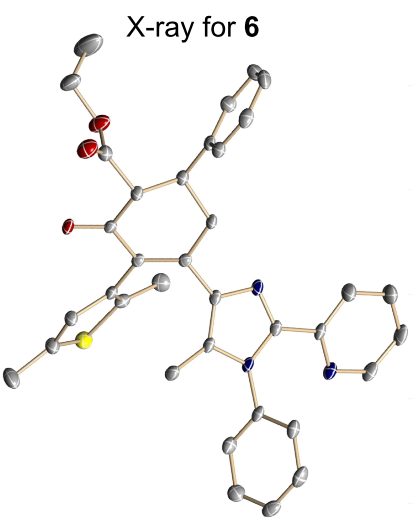<smiles>CCOC(=O)[C@H]1C(=O)C(c2ccccc2)=C(c2nc(-c3ccccn3)n(S(=O)(=O)c3ccccc3)c2N)C[C@H]1c1ccccc1</smiles>

6<smiles>Cc1csc(C2=C(c3nc(-c4ccccn4)n(-c4ccccc4)c3C)CCC2)c1</smiles>

4

ethyl 4-(2,5-dimethylthiophen-3-yl)-3-oxobutanoate:<smiles>CCOC(=O)CC(=O)Cc1cc(C)sc1C</smiles>

conditions: i: $\mathrm{AcOH}$, reflux (41\%); ii: $\mathrm{Br}_{2}, \mathrm{HBr} / \mathrm{AcOH}(90 \%)$;

iii: 1) ethyl 4-(2,5-dimethylthiophen-3-yl)-3-oxobutanoate, $\mathrm{Na}$, benzene,

2) $\mathrm{KOH}, \mathrm{H}_{2} \mathrm{O}$, EtOH (46\%);

iv: $\mathrm{Et}_{3} \mathrm{SiH}, \mathrm{CF}_{3} \mathrm{SO}_{3} \mathrm{H}, \mathrm{DCM}(51 \%)$;

v: benzaldehyde, $\mathrm{NaOH}, \mathrm{H}_{2} \mathrm{O}$, EtOH (79\%);

vi: ethyl 4-(2,5-dimethylthiophen-3-yl)-3-oxobutanoate, $\mathrm{Na}$, EtOH (57\%);

vii: $\mathrm{KOH}, \mathrm{H}_{2} \mathrm{O}$, EtOH (77\%). 
decarboxylation of $\mathbf{6}$ gave cyclohexenone 7. Thus, the previously developed methodology was successfully applied for the synthesis of a new family of photochromic ligands.

The structures of the synthesized diarylethene-based ligands $\mathbf{3}$, 4, 6, and 7 were confirmed by ${ }^{1} \mathrm{H}$ and ${ }^{13} \mathrm{C}$ NMR spectroscopy and mass spectrometry. The molecular structure of $\mathbf{6}$ was additionally confirmed by X-ray crystallography. In good accordance with previous DFT calculations [37], the molecule shows exclusively antiparallel conformation [8] of the thiophene and imidazole groups of the photoactive diarylethene moiety, with the respective $\alpha$-methyl groups pointing in different directions. The thiophene and imidazole rings are rotated out of the cyclohexenone plane by $47.7^{\circ}$ and $44.1^{\circ}$, respectively. The distance between the reactive carbon atoms is $3.6 \AA$. This value is shorter than $4.2 \AA$, which is favorable for photocyclization [38]. The cyclohexenone moiety adopts a distorted half-chair (sofa) conformation, with the phenyl substituted carbon atom forming an out-of-plane corner.

\section{Photochemical studies}

We have studied spectroscopic and photochemical properties of the ligands $3,4,6$, and 7 in nonpolar toluene and polar acetonitrile solvents. All ligands show typical for diarylethenes photochromic properties: colorless open-ring isomer and the emergence of a new band in visible upon UV light irradiation
(Figure 2) [8]. This color change is due to the reversible photocyclization and formation of a closed-ring isomer (Scheme 2).

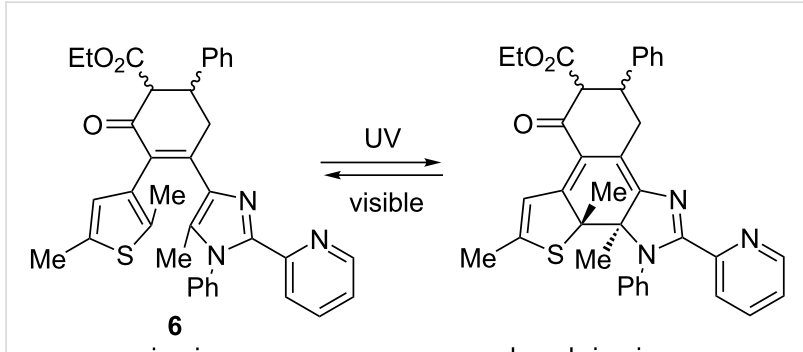

open-ring isomer

Scheme 2: Reversible photocyclization of ligand 6.

The results of photochemical studies are listed in Table 1. Absorption maxima of the open-ring ligands are in the 310-323 nm range. Interestingly, the carbocycle size and the presence/absence of carbonyl group are weakly reflected in the position of absorption maxima of open-ring isomers. For example, the reduction of carbonyl group in $\mathbf{3}$ (compared to $\mathbf{4}$ ) leads to insignificant bathochromic shift of the absorption maximum from $322 \mathrm{~nm}$ to $323 \mathrm{~nm}$ in toluene, which is, however, accompanied by a large hypochromic shift from 31100 to $20000 \mathrm{M}^{-1} \mathrm{~cm}^{-1}$. The expansion from cyclopentenone to cyclohexenone bridge gives a similar effect.

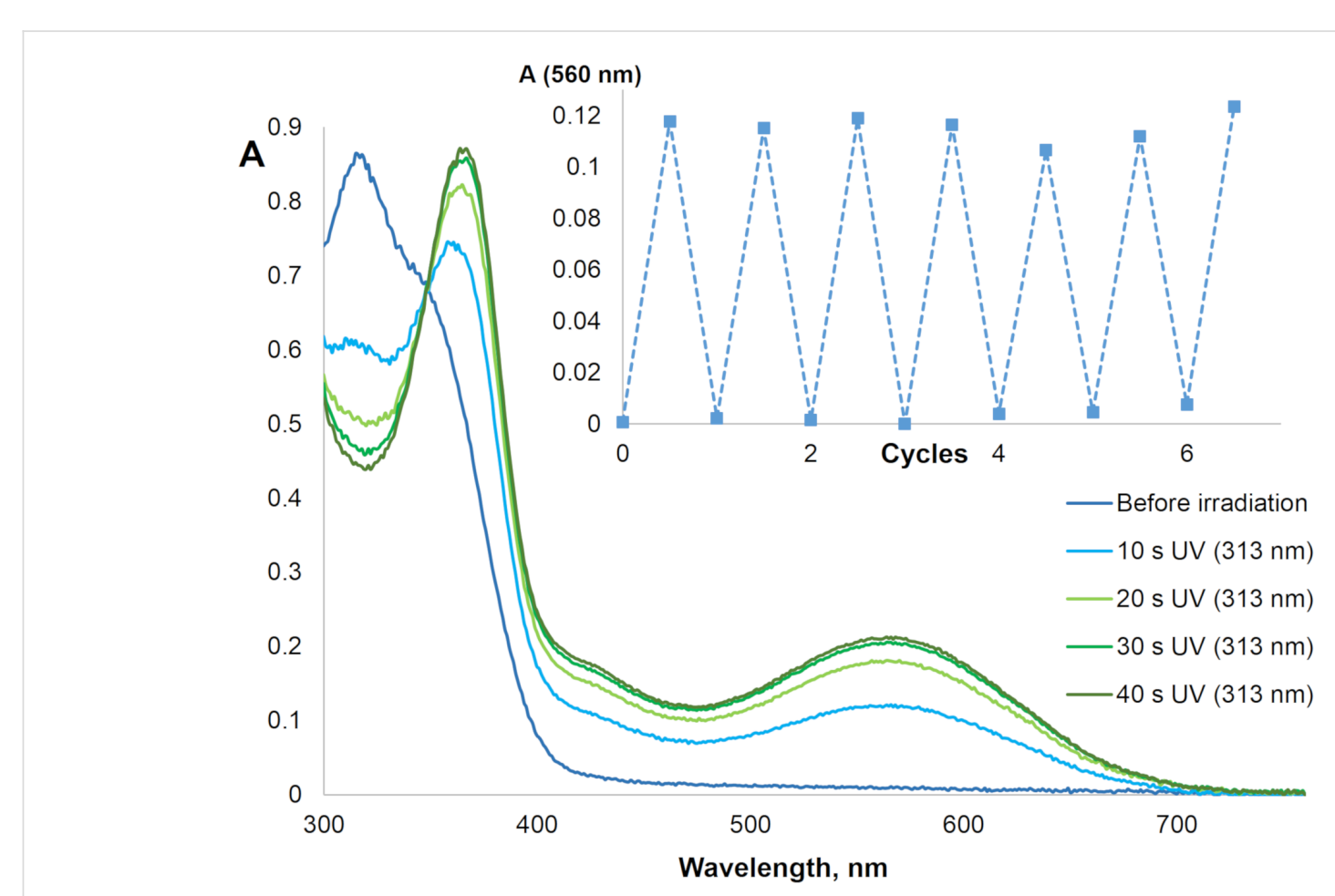

Figure 2: Electronic spectra of diarylethene 6 upon UV irradiation $\left(313 \mathrm{~nm}\right.$, toluene, $\left.c=3.4 \times 10^{-5} \mathrm{M}\right)$. Inset: fatigue resistance upon multiple subsequent irradiation with UV ( $365 \mathrm{~nm})$ and visible light (green LED) in acetonitrile. 
Table 1: Spectroscopic and photochemical properties of photochromic ligands.

\begin{tabular}{|c|c|c|c|c|c|c|c|}
\hline Diarylethene & Solvent & $\underset{\left(\varepsilon, \mathrm{M}^{-1} \cdot \mathrm{cm}^{-1}\right)^{\mathrm{a}}}{\lambda_{\max }, \mathrm{nm}}$ & $\underset{\left(\varepsilon, M^{-1} \cdot \mathrm{cm}^{-1}\right)^{\mathrm{b}}}{\lambda_{\operatorname{Bax}}, \mathrm{nm}^{-}}$ & $\Phi_{A B}{ }^{C}$ & $\Phi_{\mathrm{BA}}{ }^{\mathrm{d}}$ & $\begin{array}{l}\text { Conv } \\
\text { at PSSe }\end{array}$ & $\begin{array}{l}T^{\mathrm{BA}}{ }_{1 / 2} \\
\text { (days) }^{f}\end{array}$ \\
\hline & toluene & 322 (31100) & $572(7000)$ & 0.40 & 0.32 & 0.93 & 19.4 \\
\hline & $\mathrm{MeCN}$ & 319 (31900) & $563(6700)$ & 0.35 & 0.22 & 0.91 & 8.6 \\
\hline & toluene & 323 (20000) & $504(8400)$ & 0.42 & 0.04 & 0.89 & 19.6 \\
\hline & $\mathrm{MeCN}$ & 317 (19900) & $490(7300)$ & 0.39 & 0.06 & 0.85 & 17.0 \\
\hline & toluene & $\begin{array}{c}315(22200) \\
346(\mathrm{sh})\end{array}$ & $567(6900)$ & 0.25 & 0.29 & 0.89 & \\
\hline $1 e^{-}$ & $\mathrm{MeCN}$ & $\begin{array}{l}309(18300), \\
341(15500)\end{array}$ & $560(5200)$ & 0.26 & 0.20 & 0.91 & -g \\
\hline & toluene & $310(24200)$ & $560(5600)$ & 0.22 & 0.28 & 0.83 & 14.2 \\
\hline & $\mathrm{MeCN}$ & $310(18600)$ & $549(4800)$ & 0.27 & 0.21 & 0.70 & 13.0 \\
\hline 7 & & & & & & & \\
\hline
\end{tabular}

aAbsorption maxima (extinction coefficients) of open-ring isomers. ${ }^{b}$ Absorption maxima (extinction coefficients) of closed-ring isomers. ${ }^{c} Q u a n t u m$ yields of photocyclization under irradiation with $313 \mathrm{~nm}$. dQuantum yields of cycloreversion under irradiation with $480 \mathrm{~nm}$. ${ }^{\mathrm{e}}$ Conversion at PSS under irradiation with $313 \mathrm{~nm} .{ }^{\mathrm{f}}$ Thermal stability of the closed-ring isomer - half-life at $25{ }^{\circ} \mathrm{C}$ (days). ${ }^{9}$ Additional thermal process of photoinduced form was detected.

Cyclopentene derivative 4 shows an absorption maximum of the closed-ring isomer at $504 \mathrm{~nm}$ in toluene, while a hypsochromic shift of $14 \mathrm{~nm}$ was observed in acetonitrile. This influence of solvent polarity was detected for all ligands [39]. The carbonyl group in the ethene bridge of $\mathbf{3}$ causes a significant bathochromic shift ( $68 \mathrm{~nm}$ in toluene) of the closed-ring isomer maximum in comparison with 4 . The expansion of the five-membered carbocyclic bridge to a six-membered ring in 7 leads to a slight hypsochromic shift. The presence of a $\mathrm{CO}_{2} \mathrm{Et}$ group in the cyclohexenone bridge in 6 results in further minor hypsochromic shift. Thus, the absorption maxima of the closedring ligands are located in the wide range 490-563 nm. Photo- cyclization/cycloreversion of all ligands can be repeated several times without notable fatigue (see inset of Figure 2).

Extinction coefficients of closed-ring isomers were determined using ${ }^{1} \mathrm{H}$ NMR and electronic absorption spectroscopy (for representative NMR spectra, see section VI in Supporting Information File 1). This allowed us to determine the quantum yields of photochemical reactions. Cyclopentene (4) and cyclopentenone (3) derivatives show the highest photocyclization quantum yields up to 0.42 in toluene. In polar acetonitrile the cyclization quantum yield is lower [40]. The quantum yields for cyclohexenone derivatives 6 and 7 are in the 0.22-0.27 range. 
Similar to some other cyclopentene derivatives [41], diarylethene 4 possesses low cycloreversion quantum yields at $4-6 \%$. However, in accordance with previous results on imidazole derivatives [42], 3 with a cyclopentenone bridge shows much high quantum yields of 0.32 and 0.22 in toluene and acetonitrile, respectively. Cyclohexenone derivatives 6 and 7 show high cycloreversion quantum yields $0.20-0.29$, too. Note, that in comparison with common cyclopentene and perfluorocyclopentene derivatives [8], ligands $\mathbf{3}, \mathbf{6}$, and 7 possess high cycloreversion quantum yields. Note, that the photostationary state for the cyclization with $\lambda=313 \mathrm{~nm}$ is characterized by a high conversion to the close-ring isomers at $0.70-0.93$.

Finally, thermal stability of closed-ring isomers was determined. Previously, it was demonstrated that imidazole as a heteroaryl moiety decreases thermal stability [42]. In particular, a close analogue of $\mathbf{3}$ with a phenyl instead of a pyridyl group showed a half-live of the ring-closed isomer as low as 7.3 days. In accordance to this data, diarylethene $\mathbf{3}$ showed a half-life of 8.6 days. However, in nonpolar toluene the half-life was much higher (19.4 days). Cyclopentene and cyclohexenone derivatives 4 and 7 show similar values of thermal stability $(19.6 \mathrm{~h}$ and $14.2 \mathrm{~h}$ in toluene). Interestingly, we have detected an unexpected thermal process for the closed-ring isomer of $\mathbf{6}$ in the dark, resulted in the hypsochromic shift of long-wavelength absorption band, which could be due to keto-enol tautomerization in the ethene bridge [43]. Overall, the thermal stabilities of the new ligands are comparable to those of phenanthrolinebased photochromic ligand I [19].

\section{Synthesis and structure of iron complexes}

Previously, ligand I (Figure 1) and its analogs were successfully used in the synthesis of $\mathrm{SCO}\left[\mathrm{Fe}^{\mathrm{II}}\left(\mathrm{H}_{2} \mathrm{~B}(\mathrm{pz})_{2}\right)_{2} \mathbf{I}\right]$ complexes $(\mathrm{pz}=1$-pyrazolyl) $[19-22,44]$. We tested the ligands $\mathbf{3}, \mathbf{4}, \mathbf{6}$, and 7 for the synthesis of analogous complexes aiming at efficient light-induced SCO at rt. In all cases, the mixing of in situ-prepared " $\mathrm{Fe}\left(\mathrm{H}_{2} \mathrm{~B}(\mathrm{pz})_{2}\right)_{2}$ " with the ligands in $\mathrm{MeOH}$ resulted in the formation of red solutions. For ligand 6 bearing a $\mathrm{CO}_{2} \mathrm{Et}$ group, almost instant precipitation was observed. In contrast to $\mathbf{6}$, our attempts to obtain crystalline solids using $\mathbf{3}, \mathbf{4}$, and $\mathbf{7}$ were unsuccessful.

Crystals suitable for X-ray structure were obtained in a fritted U-shape tube by the slow diffusion of methanol solutions of in situ-prepared " $\mathrm{Fe}\left(\mathrm{H}_{2} \mathrm{~B}(\mathrm{pz})_{2}\right)_{2}$ " and diarylethene 6. Unexpectedly, we have found that the structure of the product depends on the reaction time. Reproducible crystals isolated after growing for 1 month and less - a dinuclear complex $\mathbf{8}$, and unique crystals after 2-year storage - a tetranuclear complex 9, have different molecular structures (Figure 3).
Both complexes represent unusual cyclic complexes, comprising two diarylethene ligands and two or four iron(II) ions in $\mathbf{8}$ and $\mathbf{9}$, respectively. The $\beta$-keto ester fragment in the bridge of 6 serves as a second coordination site, which eliminates a proton under the action of $\mathrm{H}_{2} \mathrm{~B}(\mathrm{pz})_{2}{ }^{1-}$ as base in both complexes [45].

The complex $8\left(\left[\mathrm{Fe}_{2}\left(\mathrm{H}_{2} \mathrm{~B}(\mathrm{pz})_{2}\right)_{2}(6-\mathrm{H})_{2}\right] \cdot 4 \mathrm{CH}_{3} \mathrm{OH}\right)$ crystallizes as red blocks in the monoclinic $C 2 / c$ space group with four molecules of $\mathbf{8}$ and 16 molecules of co-crystallized $\mathrm{CH}_{3} \mathrm{OH}$ in the unit cell. The compound reveals a crystallographically symmetrical dimeric structure with two iron centers linked by two ligands 6 . Each iron ion is coordinated equatorially by the $\beta$-keto ester moiety of one molecule $\mathbf{6}$ and chelated via the imidazole and pyridine groups of another moelcule $\mathbf{6}$. The distorted octahedral coordination sphere is completed by a $\mathrm{H}_{2} \mathrm{~B}(\mathrm{pz})_{2}{ }^{1-}$ anion. $\mathrm{Fe}-\mathrm{N}$ bond distances of $2.1602(15)-2.1615(15) \AA$ for the pyrazoles and 2.2489(14)-2.2462(14) $\AA$ for the imidazole and pyridine moieties are typical for high-spin (HS) iron(II) complexes [46,47]. Similarly, Fe-O bond distances of 1.9912(11) and 2.1238(12) A also provide evidence for HS iron(II) [46,48,49]. The two $\mathrm{Fe}-\mathrm{O}$ bonds are not equivalent as the ligand appears in its deprotonated enolate form. Furthermore, a trans-effect due to the $\mathrm{H}_{2} \mathrm{~B}(\mathrm{pz})_{2}{ }^{1-}$ anion can further elongate that bond. Two iron(II) centers are $8.057 \AA$ apart in the dimer. The ligand 6 appears in the open-ring form and the parallel conformation [8], with the $\alpha$-methyl groups pointing in similar directions. While still appearing in a distorted half-chair conformation, the phenyl substituent of the cyclohexenone moiety no longer forms the out-of-plane corner. Instead, the unsubstituted $\mathrm{CH}_{2}$ position twists out of the plane towards the thiophene moiety of another ligand 6.

Long time precipitation of crystalline material resulted in a tetranuclear species $\left[\mathrm{Fe}_{2}\left(\mathrm{H}_{2} \mathrm{~B}(\mathrm{pz})_{2}\right)_{2} \mathrm{Fe}_{2}\left(\mathrm{~B}(\mathrm{OMe})_{3}(\mathrm{pz})\right)_{2}(6-\mathrm{H})_{2}\right]$ (complex 9). Apparently, this product is the result of destruction of bis(pyrazolyl)borate moieties of complex $\mathbf{8}$ by methanol. Species 9 crystallizes as red, block-shaped crystals in the triclinic $P-1$ space group with one molecule in the unit cell. The crystal structure reveals two pairs of differently substituted iron ions connected by a so far unprecedented trimethoxypyrazolylborate bridging group. The periphery Fe ions reveal an octahedral coordination environment with two $\mathrm{H}_{2} \mathrm{~B}(\mathrm{pz})_{2}{ }^{1-}$ anions and two methoxy groups of the bridging moiety. The Fe-N bond distances ranging from 2.1361(19) to 2.1631(19) $\AA$ in 9 appear similar to those in $\mathbf{8}$, which confirms a HS-Fe(II) ion. The Fe-O bond lengths vary between 2.1333(15) $\AA$ and 2.3110(16) A. Curiously, the O-B bond distances to the tetrahedral boron ion do not differ in length with 1.453(3) and 1.449 (3) A, respectively. 

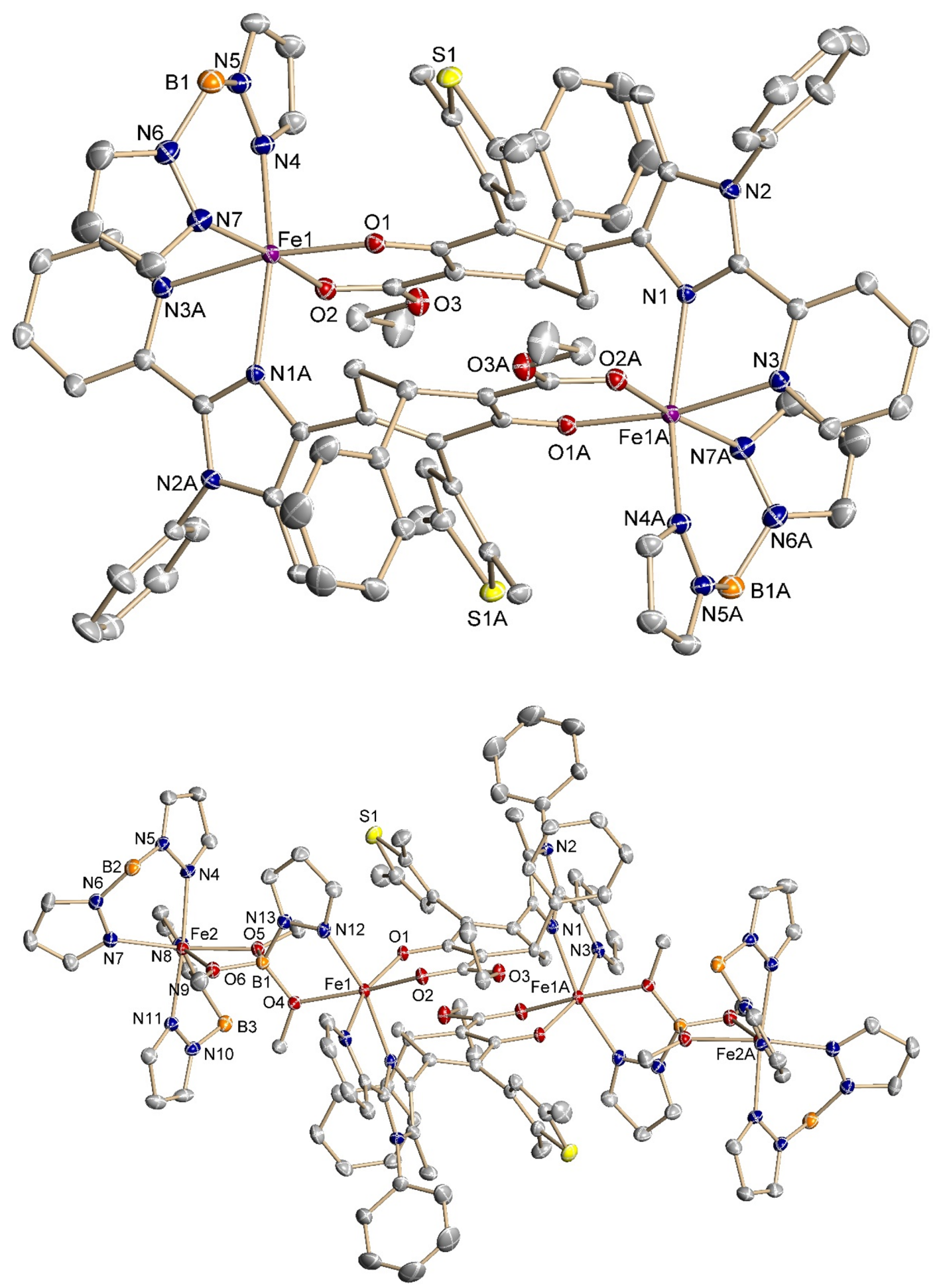

Figure 3: Molecular structure of complexes 8 (top) and 9 (bottom) at $100 \mathrm{~K}$. The $\mathrm{H}$ atoms are omitted for clarity; the thermal ellipsoids are drawn at the $50 \%$ probability level.

Each of the two interior Fe ions is linked to the bridging unit via its remaining methoxy group and the pyrazole moiety. The octahedral coordination environment is completed with the $\beta$-keto ester moiety of one ligand $\mathbf{6}$ and by the imidazole and pyridine groups of the second ligand 6 . The $\mathrm{Fe}-\mathrm{O}$ and $\mathrm{Fe}-\mathrm{N}$ bond lengths to the bridging unit are 2.1687(15) $\AA$ and 2.1190(19) $\AA$. 
The pyridine and imidazole $\mathrm{Fe}-\mathrm{N}$ bond distances are 2.2467(19) $\AA$ and 2.1793(18) $\AA$, which are very similar to those found for the dimer $\mathbf{8}$. On the contrary, the Fe-O bond distances to the $\beta$-keto ester moiety differ much less with 2.0812(15) $\AA$ and 2.0098(15) $\AA$. The iron-donor bond distances are in good agreement with an iron(II) HS state. The two iron(II) ions linked by the trimethoxypyrazolylborate group are $5.945 \AA$ apart. The distance between the iron(II) ions connected by ligand 6 in 9 is elongated by $0.244 \AA$ to $8.301 \AA$ compared to 8 . The ligand 6 appears also in its open-ring form and parallel conformation.

\section{Electronic structure of complexes $\mathbf{8}$ and $\mathbf{9}$}

Microcrystalline samples of $\mathbf{8}$ and $\mathbf{9}$ were used for magnetic susceptibility measurements. Complex $\mathbf{8}$ shows a nearly constant $\chi T$ product of $7.63 \mathrm{~cm}^{3} \cdot \mathrm{mol}^{-1} \cdot \mathrm{K}$ above $125 \mathrm{~K}$ (Figure 4). It increases gradually upon lowering the temperature, reaching a maximum of $8.80 \mathrm{~cm}^{3} \cdot \mathrm{mol}^{-1} \cdot \mathrm{K}$ at $13 \mathrm{~K}$, which is indicative of ferromagnetic coupling between the two iron(II) ions. By lowering the temperature further, the $\chi T$ product decreases sharply due to zero-field splitting (ZFS). The rt value of the $\chi T$ product of $7.63 \mathrm{~cm}^{3} \cdot \mathrm{mol}^{-1} \cdot \mathrm{K}$ is slightly higher than expected spin-only value for two non-interacting HS-Fe(II) ions $\left(\chi_{s o} T=6.00 \mathrm{~cm}^{3} \cdot \mathrm{mol}^{-1} \mathrm{~K}\right)$ due to orbital contribution. The fit for $S_{1}=S_{2}=2$ spin system (see section VII in Supporting Information File 1) affords a ferromagnetic coupling constant $J=+0.5 \mathrm{~cm}^{-1}$, axial ZFS $D=5.0 \mathrm{~cm}^{-1}$, and $g_{1}=g_{2}=2.24$. To get further insight, field dependent measurements up to $7 \mathrm{~T}$ were conducted. At fields $>4 \mathrm{~T}$ the (reduced) magnetization saturates, reaching a plateau at $8 N_{\mathrm{A}} \mu_{\mathrm{B}}$, which corresponds to two ferromagnetically coupled HS-Fe(II) ions in the ground state. Zero-field ${ }^{57} \mathrm{Fe}$ Mössbauer spectrometry confirm HS-Fe(II) state at $77 \mathrm{~K}$ and $297 \mathrm{~K}$.

The $\chi T$ product of 9 increases to almost constant value of $14.61 \mathrm{~cm}^{3} \cdot \mathrm{mol}^{-1} \cdot \mathrm{K}$ at $\mathrm{rt}$, which is in good agreement with four uncoupled HS-Fe(II) ions $\left(\chi_{s o} T=12.00 \mathrm{~cm}^{3} \cdot \mathrm{mol}^{-1} \cdot \mathrm{K}\right)$ (Figure 1). A significant drop of $\chi T$ observed at temperatures below $40 \mathrm{~K}$ is due to ZFS. The fit for $S_{1}=S_{2}=S_{3}=S_{4}=2 \mathrm{spin}$ system yields $g=2.20$ and $D=5.9 \mathrm{~cm}^{-1}$. Field-dependent magnetic measurements show a more gradual increase of magnetization compared to $\mathbf{8}$. Although the magnetization does not saturate even at $7 \mathrm{~T}$, the maximum of $14.17 N_{\mathrm{A}} \mu_{\mathrm{B}}$ points to four $S_{\mathrm{Fe}}=2$ ions $\left(16 N_{\mathrm{A}} \mu_{\mathrm{B}}\right.$ is expected $)$.

The complex 8 shows a single major absorption band in the low energy UV region at $346 \mathrm{~nm}\left(\varepsilon=6.22 \times 10^{4} \mathrm{M}^{-1} \cdot \mathrm{cm}^{-1}\right)$, which appears bathochromically shifted compared to the free ligand. No charge transfer (CT) bands are visible in the spectrum. The low intensity broad shoulder, which spans almost the entire visible region up to $750 \mathrm{~nm}$, can be attributed to $d-d$ tran-
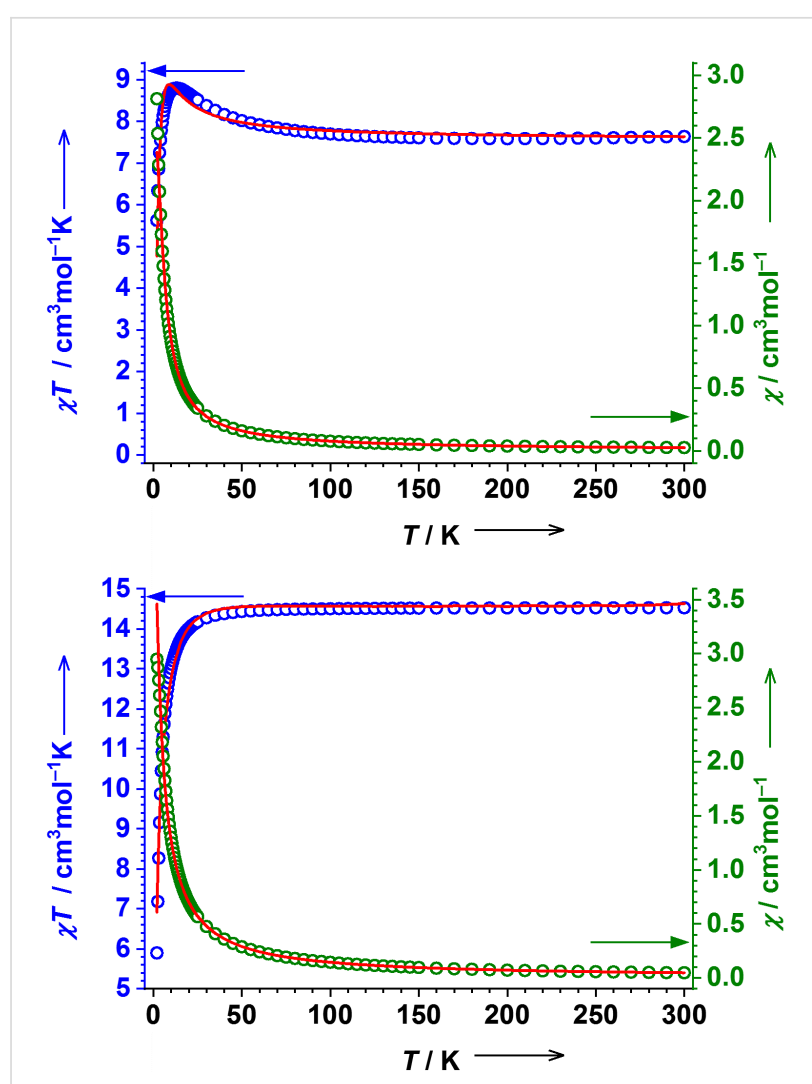

Figure 4: Variable temperature $X T$ product (blue) and $X$ (green) of 8 (top) and 9 (bottom) measured at an external magnetic field of $1 \mathrm{~T}$ in the heating mode (see Supporting Information File 1 for fitting parameters).

sitions (for details, see Supporting Information File 1). The electronic absorption spectrum of 9 shows no CT bands in the visible region. The absorption maximum at $346 \mathrm{~nm}$ $\left(\varepsilon=2.28 \times 10^{4} \mathrm{M}^{-1} \cdot \mathrm{cm}^{-1}\right)$ appears sharper compared to $\mathbf{8}$. The broad shoulder presumably due to $d-d$ transitions also appears contracted, as it disappears at lower wavelengths $(<650 \mathrm{~nm})$.

Attempts to induce photocyclization of diarylethenes in complexes 8 and 9 with UV light $(\lambda=365 \mathrm{~nm})$ in dichloromethane show no appearance of new bands. Prolonged irradiation results in slow photodecomposition. Both $\mathbf{8}$ and $\mathbf{9}$ share a common structural motif that prevents photocyclization. Coordination of the $\beta$-keto ester moiety and the imidazole/pyrazole moiety to two different iron(II) ions puts the ligand under severe strain. Thus, the structural reorganization necessary to accommodate a new planar structure formed by the photocyclization reaction is impossible without breaking $\mathrm{Fe}-\mathrm{N}$ or $\mathrm{Fe}-\mathrm{O}$ bonds.

Note, that the obtained complexes 8 and 9 represent cyclic complexes of diarylethenes with $\mathrm{Fe}(\mathrm{II})$ ions. In recent years, related derivatives of photochromic diarylethenes [50,51] became of great interest for realization of light-triggered guest uptake/ 
release [52] and light-controlled interconversion between distinct supramolecular assemblies [53]. Ligand 6 featuring two coordination sites in the heteroaryl moiety and bridge provides unique opportunities to construct novel macrocyclic systems. Our future efforts will be concentrated on the synthesis of photoactive complexes based on ligand 6 .

\section{Conclusion}

A new class of photochromic diarylethene-based ligands featuring a 2-(imidazol-2-yl)pyridine coordination unit as a heteroaryl moiety has been developed. Four members of the new family have been synthesized. All ligands show good combinations of cyclization/cycloreversion quantum yields, whereas the thermal stability of closed-ring isomers is comparable with those reported for a diarylethene-based ligand with a phenanthroline bridge. Cyclohexenone ligand 6 readily forms a dimeric complex 8 with " $\mathrm{Fe}^{\mathrm{II}}\left(\mathrm{H}_{2} \mathrm{~B}(\mathrm{pz})_{2}\right)_{2}$ ", with its $\beta$-keto ester moiety acting as a second coordination site. Slow crystallization yielded a tetranuclear Fe(II) complex 9, where the base dimeric unit is expanded by an unprecedented trimethoxypyrazolylborate bridging group. The photocyclization of iron complexes is inhibited due to the rigid coordination of the imidazole group to the metal ion, which prevents the rotation of the group needed for cyclization.

\section{Supporting Information}

\section{Supporting Information File 1 \\ Experimental details and peripheral discussion. \\ [https://www.beilstein-journals.org/bjoc/content/ supplementary/1860-5397-15-235-S1.pdf]}

\section{Supporting Information File 2}

X-ray data for compounds $\mathbf{1 , 6 , 8}$, and 9 .

[https://www.beilstein-journals.org/bjoc/content/ supplementary/1860-5397-15-235-S2.zip]

\section{Acknowledgements}

Synthesis and studies of diarylethenes were supported by the Russian Science Foundation (RSF Grant 18-73-00290). Synthesis and investigation of complexes were supported by the Deutsche Forschungsgemeinschaft (DFG Research Grant KH 279/3). MMK is grateful to Prof. Karsten Meyer (FAU Erlangen-Nürnberg) for providing access to spectroscopic facilities and his general support. Dr. Jörg Sutter (FAU ErlangenNürnberg) is acknowledged for measuring Mössbauer spectra. Prof. Yulia V. Nelyubina (INEOS RAS) is acknowledged for X-ray crystallography of compound $\mathbf{1}$. AGL thanks Deutscher Akademischer Austauschdienst for research fellowship (Forschungsstipendien - Kurzstipendien program). AGL is grateful to Felix Ruf for his invaluable support at the first stage of the project.

\section{ORCID ${ }^{\circledR}$ iDs}

Andrey G. Lvov - https://orcid.org/0000-0003-2951-2651

Frank W. Heinemann - https://orcid.org/0000-0002-9007-8404

Marat M. Khusniyarov - https://orcid.org/0000-0002-2034-421X

\section{References}

1. Ko, C.-C.; Yam, V. W.-W. Acc. Chem. Res. 2018, 51, 149-159. doi:10.1021/acs.accounts.7b00426

2. Hasegawa, Y.; Nakagawa, T.; Kawai, T. Coord. Chem. Rev. 2010, 254, 2643-2651. doi:10.1016/j.ccr.2009.12.036

3. Harvey, E. C.; Feringa, B. L.; Vos, J. G.; Browne, W. R.; Pryce, M. T. Coord. Chem. Rev. 2015, 282-283, 77-86. doi:10.1016/j.ccr.2014.06.008

4. Guerchais, V.; Ordronneau, L.; Le Bozec, H. Coord. Chem. Rev. 2010, 254, 2533-2545. doi:10.1016/j.ccr.2010.01.013

5. Bianchi, A.; Delgado-Pinar, E.; García-España, E.; Giorgi, C.; Pina, F. Coord. Chem. Rev. 2014, 260, 156-215. doi:10.1016/j.ccr.2013.09.023

6. Boillot, M.-L.; Zarembowitch, J.; Sour, A. Top. Curr. Chem. 2004, 234, 261-276. doi:10.1007/b95419

7. Kume, S.; Nishihara, H. Dalton Trans. 2008, 3260-3271. doi:10.1039/b716947g

8. Irie, M.; Fukaminato, T.; Matsuda, K.; Kobatake, S. Chem. Rev. 2014, 114, 12174-12277. doi:10.1021/cr500249p

9. Zhang, J.; Tian, H. Adv. Opt. Mater. 2018, 6, 1701278. doi:10.1002/adom.201701278

10. Lvov, A. G.; Khusniyarov, M. M.; Shirinian, V. Z. J. Photochem. Photobiol., C 2018, 36, 1-23. doi:10.1016/j.jphotochemrev.2018.04.002

11. Li, Z.-Y.; Dai, J.-W.; Damjanović, M.; Shiga, T.; Wang, J.-H.; Zhao, J.; Oshio, H.; Yamashita, M.; Bu, X.-H. Angew. Chem., Int. Ed. 2019, 58, 4339-4344. doi:10.1002/anie.201900789

12. Jukes, R. T. F.; Adamo, V.; Hartl, F.; Belser, P.; De Cola, L. Inorg. Chem. 2004, 43, 2779-2792. doi:10.1021/ic035334e

13. Ordronneau, L.; Nitadori, H.; Ledoux, I.; Singh, A.; Williams, J. A. G.; Akita, M.; Guerchais, V.; Le Bozec, H. Inorg. Chem. 2012, 51, 5627-5636. doi:10.1021/ic2025457

14. Zhong, Y.-W.; Vila, N.; Henderson, J. C.; Abruña, H. D. Inorg. Chem. 2009, 48, 7080-7085. doi:10.1021/ic802272q

15. Zhong, Y.-W.; Vila, N.; Henderson, J. C.; Abruña, H. D. Inorg. Chem. 2009, 48, 991-999. doi:10.1021/ic801588y

16. Aubert, V.; Guerchais, V.; Ishow, E.; Hoang-Thi, K.; Ledoux, I.; Nakatani, K.; Le Bozec, H. Angew. Chem., Int. Ed. 2008, 47, 577-580. doi:10.1002/anie.200704138

17. Yam, V. W.-W.; Ko, C.-C.; Zhu, N. J. Am. Chem. Soc. 2004, 126, 12734-12735. doi:10.1021/ja047446q

18. Lee, P. H.-M.; Ko, C.-C.; Zhu, N.; Yam, V. W.-W. J. Am. Chem. Soc. 2007, 129, 6058-6059. doi:10.1021/ja067425r

19. Milek, M.; Heinemann, F. W.; Khusniyarov, M. M. Inorg. Chem. 2013, 52, 11585-11592. doi:10.1021/ic401960x

20. Rösner, B.; Milek, M.; Witt, A.; Gobaut, B.; Torelli, P.; Fink, R. H.; Khusniyarov, M. M. Angew. Chem., Int. Ed. 2015, 54, 12976-12980. doi:10.1002/anie.201504192

21. Poggini, L.; Milek, M.; Londi, G.; Naim, A.; Poneti, G.; Squillantini, L.; Magnani, A.; Totti, F.; Rosa, P.; Khusniyarov, M. M.; Mannini, M. Mater. Horiz. 2018, 5, 506-513. doi:10.1039/c7mh01042g 
22. Mörtel, M.; Witt, A.; Heinemann, F. W.; Bochmann, S.; Bachmann, J.; Khusniyarov, M. M. Inorg. Chem. 2017, 56, 13174-13186. doi:10.1021/acs.inorgchem.7b01952

23. Nakagawa, T.; Hasegawa, Y.; Kawai, T. J. Phys. Chem. A 2008, 112, 5096-5103. doi:10.1021/jp712079n

24. Giraud, M.; Léaustic, A.; Charlot, M.-F.; Yu, P.; Césario, M.; Philouze, C.; Pansu, R.; Nakatani, K.; Ishow, E. New J. Chem. 2005, 29, 439-446. doi:10.1039/b409274k

25. Giraud, M.; Leaustic, A.; Guillot, R.; Yu, P.; Lacroix, P. G.; Nakatani, K.; Pansu, R.; Maurel, F. J. Mater. Chem. 2007, 17, 4414-4425. doi:10.1039/b704806h

26. Giraud, M.; Léaustic, A.; Guillot, R.; Yu, P.; Dorlet, P.; Métivier, R.; Nakatani, K. New J. Chem. 2009, 33, 1380-1385. doi:10.1039/b901201j

27. Gundogdu, L.; Kose, M.; Takeuchi, S.; Yokoyama, Y.; Orhan, E. J. Lumin. 2018, 203, 568-575. doi:10.1016/j.jlumin.2018.06.014

28. Milić, J. V.; Schaack, C.; Hellou, N.; Isenrich, F.; Gershoni-Poranne, R.; Neshchadin, D.; Egloff, S.; Trapp, N.; Ruhlmann, L.; Boudon, C.; Gescheidt, G.; Crassous, J.; Diederich, F. J. Phys. Chem. C 2018, 122, 19100-19109. doi:10.1021/acs.jpcc.8b05019

29. Peng, X.; Deng, J.-G.; Xu, H.-B. RSC Adv. 2013, 3, $24146-24153$. doi:10.1039/c3ra43110j

30. Wong, H.-L.; Zhu, N.; Yam, V. W.-W. J. Organomet. Chem. 2014, 751, 430-437. doi:10.1016/j.jorganchem.2013.07.048

31. Cao, D.-K.; Hu, J.-S.; Li, M.-Q.; Gong, D.-P.; Li, X.-X.; Ward, M. D. Dalton Trans. 2015, 44, 21008-21015. doi:10.1039/c5dt03809j

32. Lvov, A. G.; Yokoyama, Y.; Shirinian, V. Z. Chem. Rec. 2019. doi:10.1002/tcr.201900015 See for review.

33. Lettau, H. Z. Chem. 1971, 11, 10-11.

34. Crystallographic data were deposited with the Cambridge Crystallographic Data Centre (CCDC No. 1935238 (1), 1934792 (6), 1934793 (8), 1934794 (9)).

35. Shirinian, V. Z.; Shimkin, A. A.; Lonshakov, D. V.; Lvov, A. G.; Krayushkin, M. M. J. Photochem. Photobiol., A 2012, 233, 1-14. doi:10.1016/j.jphotochem.2012.02.011

36. Lvov, A. G.; Bulich, E. Y.; Metelitsa, A. V.; Shirinian, V. Z. RSC Adv. 2016, 6, 59016-59020. doi:10.1039/c6ra11791k

37. Lvov, A. G.; Kavun, A. M.; Kachala, V. V.; Nelyubina, Y. V.; Metelitsa, A. V.; Shirinian, V. Z. J. Org. Chem. 2017, 82, 1477-1486. doi:10.1021/acs.joc.6b02665

38. Kobatake, S.; Uchida, K.; Tsuchida, E.; Irie, M. Chem. Commun. 2002, 2804-2805. doi:10.1039/b208419h

39. Meng, S.; Ma, J. J. Phys. Chem. A 2012, 116, 913-923. doi:10.1021/jp210846b

40. Irie, M.; Sayo, K. J. Phys. Chem. 1992, 96, 7671-7674. doi:10.1021/j100198a035

41. Herder, M.; Schmidt, B. M.; Grubert, L.; Pätzel, M.; Schwarz, J.; Hecht, S. J. Am. Chem. Soc. 2015, 137, 2738-2747. doi:10.1021/ja513027s

42. Shirinian, V. Z.; Lvov, A. G.; Bulich, E. Y.; Zakharov, A. V.; Krayushkin, M. M. Tetrahedron Lett. 2015, 56, 5477-5481. doi:10.1016/j.tetlet.2015.08.028

43. This phenomenon was found for related dithienylethene: Lvov, A. G.; Yadykov, A. V.; Lyssenko, K. A.; Khusniyarov, M. M.; Shirinian, V. Z. Manuscript in preparation.

44. Nihei, M.; Suzuki, Y.; Kimura, N.; Kera, Y.; Oshio, H. Chem. - Eur. J. 2013, 19, 6946-6949. doi:10.1002/chem.201300767

45. Jung, O. S.; Jeong, J. H.; Sohn, Y. S. Organometallics 1991, 10 , 2217-2221. doi:10.1021/om00053a026
46. Min, K. S.; Swierczek, K.; DiPasquale, A. G.; Rheingold, A. L.; Reiff, W. M.; Arif, A. M.; Miller, J. S. Chem. Commun. 2008, 317-319. doi:10.1039/b715271j

47. Naggert, H.; Rudnik, J.; Kipgen, L.; Bernien, M.; Nickel, F.; Arruda, L. M.; Kuch, W.; Näther, C.; Tuczek, F. J. Mater. Chem. C 2015, 3, 7870-7877. doi:10.1039/c5tc00930h

48. Min, K. S.; DiPasquale, A. G.; Golen, J. A.; Rheingold, A. L.; Miller, J. S. J. Am. Chem. Soc. 2007, 129, 2360-2368. doi:10.1021/ja067208q

49. Chiou, Y.-M.; Que, L. J. Am. Chem. Soc. 1995, 117, 3999-4013. doi:10.1021/ja00119a015

50. Chen, S.; Chen, L.-J.; Yang, H.-B.; Tian, H.; Zhu, W. J. Am. Chem. Soc. 2012, 134, 13596-13599. doi:10.1021/ja306748k

51. Li, M.; Chen, L.-J.; Cai, Y.; Luo, Q.; Li, W.; Yang, H.-B.; Tian, H.; Zhu, W.-H. Chem 2019, 5, 634-648. doi:10.1016/j.chempr.2018.12.006

52. Han, M.; Michel, R.; He, B.; Chen, Y.-S.; Stalke, D.; John, M.; Clever, G. H. Angew. Chem., Int. Ed. 2013, 52, 1319-1323. doi:10.1002/anie.201207373

53. Han, M.; Luo, Y.; Damaschke, B.; Gómez, L.; Ribas, X.; Jose, A.; Peretzki, P.; Seibt, M.; Clever, G. H. Angew. Chem., Int. Ed. 2016, 55, 445-449. doi:10.1002/anie.201508307

\section{License and Terms}

This is an Open Access article under the terms of the Creative Commons Attribution License (http://creativecommons.org/licenses/by/4.0). Please note that the reuse, redistribution and reproduction in particular requires that the authors and source are credited.

The license is subject to the Beilstein Journal of Organic Chemistry terms and conditions:

(https://www.beilstein-journals.org/bjoc)

The definitive version of this article is the electronic one which can be found at: doi:10.3762/bjoc. 15.235 